\title{
Congenital Cystic Adenomatoid Malformation of Lung in an Infant
}

Hossain SMS1, Haque KN22, Sultana $\mathrm{M}^{3}$

DOI: https:/ / doi.org/ 10.3329/ jafmc.v15i2.50846

\begin{abstract}
Congenital Cystic Adenomatoid Malformation (CCAM) is considered a hamartomatous lesion of lung with excessive proliferation of bronchial structure without alveoli. We have treated a child of 12 months who presented with difficulty in breathing after birth and chest x-ray PA view shows increase lucency in the right upper zone suggestive of CCAM. Patient underwent right upper lobectomy under general anaesthesia and now she is fine.
\end{abstract}

Key-words: Congenital cystic adenomatoid malformation (CCAM), Increased luency, Lobectomy.

\section{Introduction}

Congenital Cystic Adenomatoid Malformation (CCAM) is a rare developmental anomaly1. Here there is excessive proliferation of bronchioles. The disease is usually diagnosed within one year of age and most common presentation of repeated respiratory tract infection with difficulty in breathing ${ }^{2}$. Prenatal ultrasound has a great role to identify this problem and the findings are macro cystic (single or multiple cysts $>5 \mathrm{~mm}$ ) or micro cystic (echogenic cysts $<5 \mathrm{~mm}$ ) 3 $^{\text {. }}$ Polyhydramnios has also been associated with CCAM. If not treated in time, it may turn into malignancy4.

\section{Case Report}

A 1 year female child presented with cough and difficulty in breathing for three weeks. She had fever which was intermittent in nature not associated with chills or rigor and treated with antibiotics, bronchodilators but not improved satisfactorily. On examination, she was ill looking there was no chest indrawing, chest movement reduced in the right side, trachea shifted to the left, hyper resonant percussion notes and there was coarse crepitation in the right upper chest. Blood $\mathrm{CBC}$ consistent with anemia and leucocytosis. Chest X-ray P/A view shows hyperlucency in right upper and mid zone (Figure-1). HRCT scan of chest shows large well defined cyst in the right upper lobe with contralateral herniation of the lung (Figure-2). The diagnosis was Congenital Cystic Adenomatoid Malformation (CCAM) Right. She underwent right upper lobectomy under GA with single lung ventilation. Postoperatively the child was kept intubated in the pediatric ICU. On 3id postoperative day, she was extubated and improved satisfactorily.

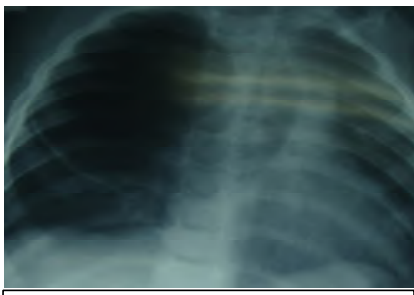

Figure-1: X-ray chest P-A view shows hyperlucency in right upper and mid zone

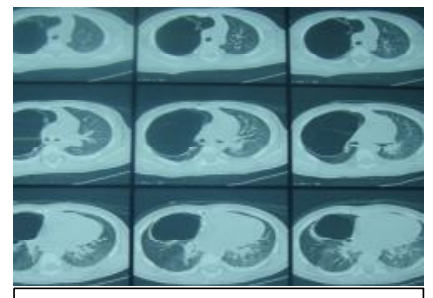

Figure-2: CT scan shows large well defined cystic lesion occupying right upper lobe

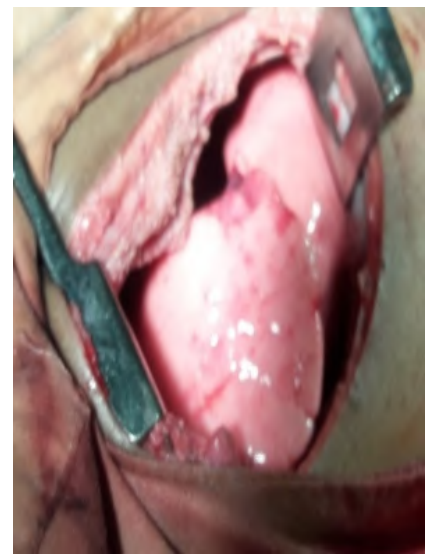

Figure-3: Right upper lobectomy, the inflated middle and lower lobe

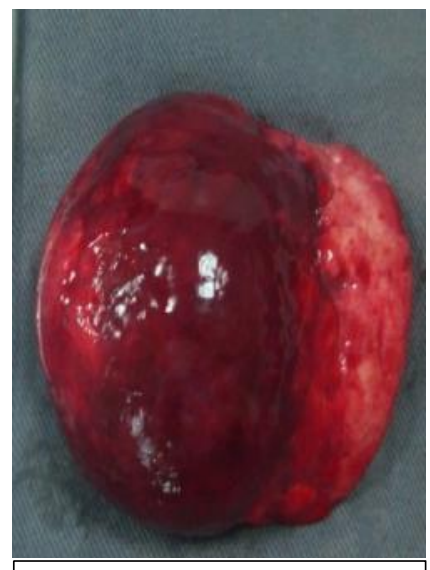

Figure-4: Resected specimen of right upper lobe

\section{Discussion}

Congenital cystic adenomatoid malformation is rare congenital anomaly appearing as cyst or lump in the chest that can vary in size. It is the most common type of lung lesion and is diagnosed prenatally with antenatal care. Development of hydrops fetalis with essentially fetal congestive cardiac failure is poor prognostic sign. Pulmonary hypoplasia and mediastinal shift are frequently present. CCAM is diagnosed prenatally when an ultrasound shows a cystic or solid lung tumour ${ }^{5}$. Stocker described the lesion of three types: (a) TypeI (70\%): single or multiple cysts larger than $2 \mathrm{~cm}$ diameter, (b) Type II (20\%): Mixture of intermediate type cyst between 0.5 to $2 \mathrm{~cm}$ in diameter and (c) Type III (10\%): Multiple cysts less than $0.5 \mathrm{~cm}$ in diameter, mostly solid with predominantly adenomatoid tissue.

Newborn, typically present with; respiratory distress, recurrent pneumonia and poor feeding. CCAM can be confused with bronchopulmonary sequestration, which may also present as a solid mass. A color flow doppler ultrasound can confirm the diagnosis of sequestration. CCAM may present in the older child and adults as an incidental finding or secondary to repeated infection ${ }^{5,6}$. Lobectomy can be performed safely with minimum morbidity. Surgery at the very beginning also maximizes lung growth7,8.

\section{Conclusion}

Surgery is the treatment of choice if diagnosed early to prevent the risks of repeated respiratory tract infection and subsequent malignant transformation. Lobectomy is commonly performed procedure, but wedge or segmental resection is also feasible. 


\section{References}

1. Wilson RD, Hedrick HL, Liechty KW et al. Cystic adenomatoid malformation of the lung: Review of genetics, prenatal diagnosis and in utero treatment. Am J Med Genet A 2006; 140(2):151-5.

2. Kim WS, Lee KS, Kim IO et al. Congenital Cystic Adenomatod Malformation of the Lung: CT-Pathologic Correlation. AJR Am J Roentgenol 1997; 168(1):47-53.

3. Adzick NS, Harrison MR, Crombleholme TM et al. Fetal lung lesions: management and outcome. Am J Obstet Gynecol 1998; 179(4):884-9.

4. Sauvat $F$, Michel JL, Benachi $A$ et al. Management of asymptomatic neonatal cystic adenomatoid malformation. J Pediatr Surg $2003 ; 38(4): 548-52$.
5. Laberge JM, Flageole $H$, Pugash $D$ et al. Outcome of the prenatally diagnosed CCAM: A Canadian experience. Fetal Diagn Ther 2001; 16(3):178-86.

6. Parikh D, Samuel M. Congenital cystic lung lesions: Is surgical resection essential? Padiatr Pulmonol 2005; 40(6):533-7.

7. Miller JA, Corteville JE, Langer JC. CCAM in the fetus; Natural History and Predictors of outcome. J Pediatr Surg 1996; 31(6):805-8.

8. Heij HA, Ekkelkamp S, Vos A. Diagnosis of CCAM of the lung in newborn infants and children. Thorax 1990; 45(2):122-5. 